\title{
The pricing of anomalies using factor models: a test in Latin American markets*
}

\author{
Gabriel Augusto de Carvalho' \\ (D) https://orcid.org/0000-0002-3908-1552 \\ Email: ga09carvalho@gmail.com \\ Hudson Fernandes Amaral ${ }^{2}$ \\ (D) https://orcid.org/0000-0001-8455-0285 \\ Email: hudson.amaral@unihorizontes.br \\ Juliano Lima Pinheiro ${ }^{3}$ \\ (D) https://orcid.org/0000-0003-0715-2237 \\ Email: julianopinheiro@face.ufmg.br \\ Laíse Ferraz Correia ${ }^{4}$ \\ (D) https://orcid.org/0000-0002-0977-9298 \\ Email: laise@cefetmg.br
}

\begin{abstract}
${ }^{1}$ Centro Federal de Educação Tecnológica de Minas Gerais, Programa de Pós-Graduação em Administração, Belo Horizonte, MG, Brazil
${ }^{2}$ Centro Universitário Unihorizontes, Programa de Mestrado Acadêmico em Administração, Belo Horizonte, MG, Brazil

${ }^{3}$ Universidade Federal de Minas Gerais, Faculdade de Ciências Econômicas, Departamento de Ciências Contábeis, Belo Horizonte, MG, Brazil

${ }^{4}$ Centro Federal de Educação Tecnológica de Minas Gerais, Programa de Pós-Graduação em Administração, Belo Horizonte, MG, Brazil
\end{abstract}

Received on 06.16.2020 - Desk acceptance on 08.13.2020 - $3^{\text {rd }}$ version approved on 02.02.2021 - Ahead of print on 07.23.2021

Editor-in-Chief: Fábio Frezatti

Associate Editor: Fernanda Finotti Cordeiro

\section{ABSTRACT}

This article aimed to test the five-factor model in Latin American emerging markets. In order to verify which set of factors best fits the data, the three- and four-factor models were also estimated. Asset pricing models have been proposed within the context of developed markets, with few empirical tests of these models performed based on emerging markets' data. This study is based on the differences between the markets of developed and emerging countries, which affect the models' predictive power and, thus, the investors' decision-making process. The study also provides evidence that contributes to a more assertive decision-making by all financial market players. In addition, the study results suggest an opportunity to carry out tests with the inclusion of new factors in the models. The study sample included assets listed on stock exchanges in Brazil, Chile, Colombia, Mexico and Peru between June 1999 and June 2017. The building of the factors was based on the return differential between portfolios formed based on the characteristics of the assets, and the models were estimated using the two-step regression methodology. The results for the first- and second-step regressions indicated that the five-factor model had the best predictive power. However, in the second-step estimation, none of the models was able to fully explain the returns on the portfolios. Our conclusion is that the five-factor model showed the best performance for the sample, although there may be other relevant factors that could be incorporated into it. The main contribution of this article lies in the better knowledge it provides of the relevant factors for the asset pricing in emerging markets.

Keywords: asset pricing, factor models, pricing factors, emerging markets, Latin America.

Correspondence address

Gabriel Augusto de Carvalho

Centro Federal de Educação Tecnológica de Minas Gerais Departamento de Ciências Sociais Aplicadas

Avenida Amazonas, 7675 - CEP 30510-000

Nova Gameleira - Belo Horizonte - MG - Brasil

*The authors would like to thank the Centro Federal de Educação Tecnológica de Minas Gerais (CEFET-MG) for the financial support provided to this study. 


\section{INTRODUCTION}

Studies on asset pricing seek to identify the relevant factors to the return generating process, thus achieving a better understanding of investors' decision-making and, consequently, of the behavior of asset prices. The Capital Asset Pricing Model (CAPM), based on the works of Sharpe (1964), Lintner (1965) and Mossin (1966), is a single factor model that describes the asset's expected return according to its level of systematic risk.

As Fama and French (2004) point out, the empirical evidences of the CAPM is poor and, therefore, theoretical and empirical factor models have been proprosed. Merton (1973) proposed the Intertemporal Capital Asset Pricing Model (ICAPM), a model in which the return generating process is explained through several factors. And, working under the main assumption of the absence of market arbitrage opportunities, Ross (1976) developed the Arbitrage Pricing Theory (APT) as an alternative approach to explain the return generating process, which also assumes that several factors can be used to describe assets' returns. These models were used in several empirical tests of the return generating process to analyze the process of pricing anomalies observed in the markets. Among these models, the three-factor model by Fama and French (1993), the four-factor model by Carhart (1997) and the five-factor model by Fama and French (2015) stand out.

As pointed out by Cakici, Fabozzi and Tan (2013) and Leite, Klotzle, Pinto and Silva (2018), most of the studies on asset pricing were conducted in developed markets, and despite the increasing importance of emerging countries' capital markets, there are few models capable of adequately explaining the return generating process in emerging markets. Leite et al. (2018) characterize emerging markets by the lower quality of available data, political and institutional instability and greater vulnerability to speculative capital. Harvey (1995) points out that the exposure of assets traded in emerging markets to the pricing factors commonly used in the literature is low. Such aspects can affect the rationality of the investors' decision making and also the ability of pricing models to describe assets' returns in these markets.

Cakici et al. (2013), Cakici, Tang and Yan (2016), Zaremba and Czapkiewicz (2017), Foye (2018) and Leite et al. (2018) are examples of studies that, in developing empirical tests of asset pricing models, used samples of assets traded in emerging markets. The results of these studies pointed, in general, to a low predictive power of models for emerging markets, and also found evidence of market segmentation in relation to developed economies.

Latin America is characterized by a variety of emerging markets among the countries that comprise it. Morgan Stanley Capital International (MSCI) included five markets in the region in the composition of its Emerging Markets Index for August 2018, namely: Brazil, Chile, Colombia, Mexico and Peru. According to data from the World Federation of Exchanges (WFE), in August 2018 more than 1000 companies were listed in these five countries' markets, totaling a market capitalization of more than US $\$ 1.7$ trillion.

All this shows there is an opportunity to contribute to the literature on the theme of asset pricing in emerging economies. Thus, the main objective of this article was to test the five-factor model of Fama and French (2015) in the context of the main Latin American emerging markets. As this model is an evolution of the three-factor model of Fama and French (1993), on which Carhart (1997) based his four-factor model, these two models were also estimated in our research. That is, we sought to assess the combination of factors that best explains the asset returns in the sample.

As a practical contribution of our study, we expect our findings to reveal the main relevant factors and allow market investors, company managers and capital markets regulators a more confident decision-making process. The study's contribution to the specialized literature is mainly focused on providing new evidence on pricing anomalies in emerging markets.

In addition to this introduction, this article has four other sections. The second section presents a general review of the literature on asset pricing theory and some empirical tests developed in emerging markets. The third section describes the methodological procedures used in our study. Our results are presented and analyzed in the fourth section. Finally, the last section provides comments on our objectives and presents our final considerations. 


\section{THEORETICAL FRAMEWORK}

\subsection{Capital Asset Pricing}

The CAPM of Sharpe (1964), Lintner (1965) and Mossin (1966) describe the asset pricing under risk. According to this model, the return on an asset is given by the return on risk-free assets plus a premium for the asset's market risk. To measure market risk, CAPM uses the beta coefficient, which measures the sensitivity of the asset's return to the variance of the market return. This model is therefore characterized by a linear relationship between risk and return, with the presence of a single factor: the beta coefficient.

Ross (1976) proposed the Arbitrage Pricing Theory (APT) as an alternative approach to asset pricing, which allows some CAPM's assumptions to be relaxed. Based on the law of one price, APT assumes the impossibility of obtaining arbitrage profits - differences between prices, which allow profits to be obtained without risk, are immediately eliminated - assumes homogeneous expectations and considers the need for a large number of available assets, which makes the non-systematic risk of a diversified portfolio negligible.

This new approach suggests the existence of other factors capable of explaining the return generating process of assets. That is, APT assumes that returns are described by a multi-factor model. In line with this proposition, Fama and French (1992) showed that CAPM's explanatory power increases with the inclusion of other sources of risk in the model and, thus, corroborated the multidimensional nature of systemic risk.

Since then, different anomalies have been tested in the development of multi-factor asset pricing models. Fama and French (1993) proposed a model that incorporates, in addition to market return, factors related to firm size and book-to-market ratio. The model was thus composed of three factors, namely: the premium for the market factor, measured by the excess return on the market portfolio; the small minus big factor (SMB), measured by the difference in return between portfolios composed of smaller and larger market capitalization companies; and the high minus low factor (HML), measured by the return differential between portfolios composed by companies with the highest and the lowest bookto-market ratios.

Carhart (1997) proposed the addition of the momentum factor as an explanatory variable for asset returns to the three-factor model by Fama and French
(1993), thus developing a four-factor model. To build the winners minus losers (WML) factor, Carhart (1997) measured by the differential return between portfolios of the winners and losers stocks.

Based on the empirical evidence from studies carried out in the 2000s - such as those by Fama and French (2006, 2008), Titman, Wei and Xie (2004) and Novy and Marx (2013) - Fama and French (2015) verified that investment and profitability anomalies are left unexplained by the three-factor model. In view of this evidence, Fama and French (2015) proposed the five-factor model, which consisted of the addition of robust minus weak (RMW) - difference in returns between portfolios formed by high and low profitability stocks - and conservative minus aggressive (CMA) - difference between the returns on portfolios composed of low- and high-investment stocks - to the three-factor model.

\subsubsection{Assets pricing in emerging markets}

Carhart (1997) and Fama and French $(1993,2015)$ developed their models based on empirical tests carried out with North American market data. However, it should be taken into account that the particularities of emerging markets can affect investors' decision-making and, consequently, the predictive power of pricing factors. Thus, an increasing number of studies have been focusing on the development of empirical tests of pricing models based on data from emerging countries.

In a pioneering study, Harvey (1995) researches asset pricing in a sample composed of 800 stocks from 20 emerging markets. The author tests a global version of the CAPM and his results indicate that the model is not capable of explaining the returns on assets in emerging markets. As a result, it is pointed out that emerging markets are not fully integrated into the world capital markets, and that there are other systematic risk factors that affect asset pricing in those markets.

Similarly, later studies have also compared the performance of models that consider global factors with versions that include factors based on emerging markets data. Authors such as Cakici et al. (2013), Hanauer and Linhart (2015) and Leite et al. (2018) used this strategy in their studies and pointed out that, compared with models using global factors, models based on local factors showed a greater predictive power, which is evidence of segmentation of emerging markets from developed markets, as pointed out by Harvey (1995). 
In addition to the segmentation of developed and emerging markets, studies including emerging markets in their samples also look into other aspects. Authors such as Cakici et al. (2016), Foye (2018) and Leite et al. (2018) observed differing behaviors in average factor returns between: (i) different emerging markets; and (ii) emerging and developed markets. This pattern of differing results across different markets was also observed by the authors in the statistical significance analysis of pricing factors.

The characteristics and patterns observed in assets traded in emerging markets have theoretical and practical implications. As Leite et al. (2018) points out, pricing models generally perform poorly in explaining the asset returns in emerging countries compared with results for developed countries. For the investor, these emerging markets' characteristics may present an opportunity. As pointed out by Harvey (1995), a global investor, by allocating part of its resources in emerging markets, can benefit from a greater diversification in its portfolio.

Table 1 below presents a summary with some of the main recent studies on asset pricing prepared with emerging markets' data.

\section{Table 1}

Empirical studies on asset pricing using samples from emerging markets

\begin{tabular}{|c|c|c|c|}
\hline Authors & Sample & Factors included & Main findings \\
\hline Cakici et al. (2013) & 18 emerging markets & $\begin{array}{l}\text { Market; size; value; and } \\
\text { momentum }\end{array}$ & $\begin{array}{l}\text { Local factors showed a better predictive power } \\
\text { compared with American and global factors. }\end{array}$ \\
\hline $\begin{array}{l}\text { Hanauer and Linhart } \\
\text { (2015) }\end{array}$ & 21 emerging markets & $\begin{array}{l}\text { Market; size; value; and } \\
\text { momentum }\end{array}$ & $\begin{array}{l}\text { The model with the greater predictive power was } \\
\text { based on Carhart (1997) and used local factors. }\end{array}$ \\
\hline Cakici et al. (2016) & 18 emerging markets & $\begin{array}{l}\text { Market; size; value; and } \\
\text { momentum }\end{array}$ & $\begin{array}{l}\text { The value and momentum factors fail to explain } \\
\text { asset returns. }\end{array}$ \\
\hline Xie and Qu (2016) & $\begin{array}{l}\text { Shanghai Stock Exchange } \\
\text { (SSE) }\end{array}$ & Market; size; and value & $\begin{array}{l}\text { The model of Fama and French (1993) performed } \\
\text { well, being able to increase the predictive power } \\
\text { compared with CAPM. }\end{array}$ \\
\hline $\begin{array}{l}\text { Siqueira, Amaral and } \\
\quad \text { Correia (2017) }\end{array}$ & Brazilian Market (B3) & $\begin{array}{l}\text { Market; size; value; momentum; } \\
\text { investment; profitability; and } \\
\text { volume-synchronized probability } \\
\text { of informed trading (VPIN) }\end{array}$ & $\begin{array}{l}\text { The VPIN factor increased the models' } \\
\text { explanatory power. The model that performed } \\
\text { better was composed of market, size, investment, } \\
\text { profitability and VPIN factors. }\end{array}$ \\
\hline $\begin{array}{c}\text { Zaremba and } \\
\text { Czapkiewicz (2017) }\end{array}$ & $\begin{array}{l}5 \text { Eastern-European } \\
\text { emerging markets }\end{array}$ & $\begin{array}{l}\text { Market; size; value; momentum; } \\
\text { investment; and profitability }\end{array}$ & $\begin{array}{l}\text { The model of Fama and French (2015) best } \\
\text { explains the returns of anomaly portfolios. }\end{array}$ \\
\hline Foye (2018) & 18 emerging markets & $\begin{array}{l}\text { Market; size; value; investment; } \\
\text { and profitability }\end{array}$ & $\begin{array}{l}\text { The factors used by Fama and French (2015) } \\
\text { offered a better description of returns in Eastern } \\
\text { Europe and Latin America, whereas for Asia this } \\
\text { model failed to increase the explanatory power of } \\
\text { the model of Fama and French (1993). }\end{array}$ \\
\hline Leite et al. (2018) & 12 emerging markets & $\begin{array}{l}\text { Market; size; value; investment; } \\
\text { and profitability }\end{array}$ & $\begin{array}{l}\text { The models of Carhart (1997) and Fama and } \\
\text { French (2015) performed better, the value factor } \\
\text { showed to be redundant in the model of Fama } \\
\text { and French (2015). }\end{array}$ \\
\hline $\begin{array}{l}\text { Ali, Khurram and Jiang } \\
\text { (2019) }\end{array}$ & Pakistan's Market & $\begin{array}{l}\text { Market; size; value; momentum; } \\
\text { investment; and profitability }\end{array}$ & $\begin{array}{l}\text { The model using the factors of Fama and French } \\
\text { (2015) showed the greater predictive power. An } \\
\text { important point is that the momentum and value } \\
\text { factors were redundant. }\end{array}$ \\
\hline $\begin{array}{l}\text { Ganz, Schlotefeldt and } \\
\text { Rodrigues Junior (2020) }\end{array}$ & Brazilian Market (B3) & $\begin{array}{l}\text { Market; size; value; investment; } \\
\text { profitability; and corporate } \\
\text { governance }\end{array}$ & $\begin{array}{l}\text { Results showed that the market risk factor } \\
\text { was the only significant one, regardless of the } \\
\text { combination of factors tested. }\end{array}$ \\
\hline
\end{tabular}

Source: Elaborated by the authors.

These studies' findings provide further evidence of the relevance of the subject of asset pricing in emerging markets. The results of Foye (2018) stand out in suggesting divergences in the models' predictive power for the different regions studied. Hence the pertinence of carrying out further studies on this theme, while also taking into account these markets' regional peculiarities. 


\section{METHODS}

\subsection{Population and Sample}

This study population consisted of all the stocks listed on the stock exchanges of Latin American emerging markets between June 1, 1999 and June 30, 2017. The countries included in the sample were selected based on the MSCI Emerging Markets Latin America Index for August 2018, which included the markets of Brazil, Chile, Colombia, Mexico and Peru.

In the sampling process, we initially excluded stocks of financial firms. As pointed out by Fama and French (1992), the high leverage of these firms does not mean the same for firms in other sectors. Then, given the data limitation for many stocks that remained in the sample, only companies for which the information described below were available in the database were considered in each year studied:

a. Positive equity and market value as of December 31 of the previous year, with a tolerance of minus 30 days for the second variable; b. Total assets as of December 31 of the two years preceding the portfolio formation;

c. Operating profit as of December 31 of the year before the portfolio formation;

d. Market value as of June 30, with a tolerance of minus 30 days;

e. Stocks that had consecutive monthly trades and at least one trade per month, for the period of 12 months before and after the date of portfolio formation.

Table 2 shows the annual sample composition, segregated by the different markets considered in the study. Note the relevance of the Brazilian market compared with the other markets in the region, which is due to the greater number of assets that meet the study criteria established. At the other extreme is Colombia, the market with the lowest number of assets in the overall sample.

Table 2

Sample composition

\begin{tabular}{|c|c|c|c|c|c|c|}
\hline & Brazil & Chile & Colombia & Mexico & Peru & Total \\
\hline 2000 & 109 & 70 & 8 & 65 & 21 & 273 \\
\hline 2001 & 119 & 63 & 8 & 69 & 25 & 284 \\
\hline 2002 & 123 & 61 & 9 & 61 & 29 & 283 \\
\hline 2003 & 128 & 65 & 9 & 58 & 31 & 291 \\
\hline 2004 & 141 & 64 & 9 & 58 & 35 & 307 \\
\hline 2005 & 144 & 68 & 7 & 60 & 40 & 319 \\
\hline 2006 & 161 & 78 & 6 & 60 & 47 & 352 \\
\hline 2007 & 178 & 88 & 6 & 58 & 48 & 378 \\
\hline 2008 & 211 & 81 & 5 & 58 & 51 & 406 \\
\hline 2009 & 229 & 76 & 7 & 66 & 49 & 427 \\
\hline 2010 & 231 & 84 & 7 & 67 & 47 & 436 \\
\hline 2011 & 223 & 92 & 8 & 71 & 44 & 438 \\
\hline 2012 & 233 & 84 & 9 & 69 & 37 & 432 \\
\hline 2013 & 224 & 84 & 12 & 67 & 35 & 422 \\
\hline 2014 & 215 & 86 & 19 & 66 & 31 & 417 \\
\hline 2015 & 201 & 82 & 17 & 70 & 26 & 396 \\
\hline 2016 & 192 & 78 & 20 & 73 & 27 & 390 \\
\hline 2017 & 197 & 80 & 21 & 71 & 28 & 397 \\
\hline
\end{tabular}

Source: Elaborated by the authors. 
After selecting the markets to be studied and, based on them, the final study sample, the data necessary for developing the estimated models were collected on the Bloomberg financial information platform. As this study included markets in different countries, all monetary values were converted into US dollars to enable comparisons.

\subsection{Econometric Models Estimated}

The model testing procedure was structured in two steps, according to the methodology of Fama and MacBeth (1973). Table 3 shows the econometric models estimated in the first step (time series regressions), which were estimated to obtain the slope coefficients $\left(\beta_{\mathrm{i}}, \mathrm{s}_{\mathrm{i}}, \mathrm{h}_{\mathrm{i}}, \mathrm{w}_{\mathrm{i}}, \mathrm{r}_{\mathrm{i}}, \mathrm{c}_{\mathrm{i}}\right)$.

Table 3

Econometric models used in the first step

\begin{tabular}{ccc}
\hline Model & Equation & Empirical basis \\
\hline Three-factor & $\mathrm{R}_{\mathrm{i}}-\mathrm{R}_{\mathrm{f}}=\alpha_{\mathrm{i}}+\beta_{\mathrm{i}}\left(\mathrm{R}_{\mathrm{m}}-\mathrm{R}_{\mathrm{f}}\right)+\mathrm{s}_{\mathrm{i}} \mathrm{SMB}+\mathrm{h}_{\mathrm{i}} \mathrm{HML}+\varepsilon_{i}$ & Fama and French (1993) \\
\hline Four-factor & $\mathrm{R}_{\mathrm{i}}-\mathrm{R}_{\mathrm{f}}=\alpha_{\mathrm{i}}+\beta_{\mathrm{i}}\left(\mathrm{R}_{\mathrm{m}}-\mathrm{R}_{\mathrm{f}}\right)+\mathrm{s}_{\mathrm{i}} \mathrm{SMB}+\mathrm{h}_{\mathrm{i}} \mathrm{HML}+\mathrm{w}_{\mathrm{i}} \mathrm{WML}+\varepsilon_{\mathrm{i}}$ & Carhart (1997) \\
\hline Five-factor & $\mathrm{R}_{\mathrm{i}}-\mathrm{R}_{\mathrm{f}}=\alpha_{\mathrm{i}}+\beta_{\mathrm{i}}\left(\mathrm{R}_{\mathrm{m}}-\mathrm{R}_{\mathrm{f}}\right)+\mathrm{s}_{\mathrm{i}} \mathrm{SMB}+\mathrm{h}_{\mathrm{i}} \mathrm{HML}+\mathrm{r}_{\mathrm{i}} \mathrm{RMW}+\mathrm{c}_{\mathrm{i}} \mathrm{CMA}+\varepsilon_{\mathrm{i}}$ & Fama and French (2015) \\
\hline
\end{tabular}

Note: The coefficients of the market premium, size, book-to-market, momentum, profitability and investment factors are represented by $\beta_{i,} s_{i,} h_{i}, w_{i,} r_{i}$ and $c_{i}$ respectively. The intercept of the models is represented by $\alpha_{i}$.

Source: Elaborated by the authors.

These slope coefficients were then used as explanatory variables for the cross-section regression models estimated in the second step, which were used to test the statistical significance of the factors linked to them. Table 4 shows the econometric models estimated in the second step.

Table 4

Econometric models estimated in the second step

\begin{tabular}{ccc}
\hline Model & Equation & Empirical basis \\
\hline Three-factor & $\overline{\mathrm{R}}=\gamma_{0}+\gamma_{1} \beta+\gamma_{2} s+\gamma_{3} \mathrm{~h}+\varepsilon_{i}$ & Fama and French (1993) \\
\hline Four-factor & $\overline{\mathrm{R}}=\gamma_{0}+\gamma_{1} \beta+\gamma_{2} s+\gamma_{3} \mathrm{~h}+\gamma_{4} \mathrm{w}+\varepsilon_{\mathrm{i}}$ & Carhart (1997) \\
\hline Five-factor & $\overline{\mathrm{R}}=\gamma_{0}+\gamma_{1} \beta+\gamma_{2} s+\gamma_{3} \mathrm{~h}+\gamma_{5} \mathrm{r}+\gamma_{6} \mathrm{c}+\varepsilon_{\mathrm{i}}$ & Fama and French (2015) \\
\hline
\end{tabular}

Note: The coefficients of the market premium, size, book-to-market, momentum, profitability and investment factors are represented by $\gamma_{1}, \gamma_{2}, \gamma_{3}, \gamma_{4}, \gamma_{5}$ and $\gamma_{6^{\prime}}$ respectively. The intercept of the models is represented by $\gamma_{0}$.

Source: Elaborated by the authors.

Below we detail the methods used to build the portfolios and calculate their returns (dependent variables of the first- and second-step models); as well as the methods for building the factors used as independent variables in the first-step models. The procedures used in the building of factors, estimation of models and statistical tests were performed using Python and $\mathrm{R}$ programming languages.

\subsubsection{Independent variables}

We adopted a strategy similar to that of Fama and French $(1993,2015)$ for building the factors and formed the study portfolios based on the sample stocks' characteristics. This involved initially ranking the stocks from small to big market capitalization - obtained by multiplying the stock price by the number of stocks outstanding - which were then divided into two groups by the median. As a result, a Small (S) and a Big (B) group were created, the former consisting of stocks with market capitalization below the median of the sample's market value and the latter consisting of stocks with market capitalization above that value.

The stocks composing the two groups formed by size were ranked again independently, according to the 
values for the other study variables, and then divided into groups based on the 30th and 70th percentiles. For the book-to-market ratio - obtained by the ratio between equity and market value - the High $(\mathrm{H})$, Neutral (N) and Low (L) portfolios were formed, which were used to build the HML factor. For the momentum variable (cumulative stock return between months $t-12$ and $t-2$ ), the groups Winner (Win), Neutral (N) and Loser (Los) were formed, which were used to build the WML factor.

Finally, for the factors added by Fama and French (2015), the Robust (R), Neutral (N) and Weak (W) groups were formed for profitability (ratio between operating profit and equity), and the Conservative (C), Neutral (N) and Agressive (A) groups were formed for investment (growth of the firm's total assets between the years $t-1$ and $t$ ), which were used to build the RMW and CMA factors, respectively.
After performing this procedure, six portfolios were obtained for each variable used in the second ranking; and then the monthly returns on each portfolio were calculated. To obtain the portfolio returns, we used the individual monthly log returns on the stocks weighted by the market value of each asset in relation to the portfolio's total market value. The portfolio formation procedure was performed again every June of the sample period (2000 to 2017) in order to allow new information to be incorporated into the portfolios' composition.

Table 5 details the procedure used to build the factors. Our methodology followed that of Fama and French (1993, 2015), using the difference between the average returns on different portfolio groups. It is also worth mentioning that, as in Fama and French (1993) and Carhart (1997), the SMB factor used in the estimation of the three- and four-factor models was composed only by the $\mathrm{SMB}_{\mathrm{B} / \mathrm{M}}$ factor.

\section{Table 5}

Building of the factors

\begin{tabular}{|c|c|c|}
\hline Variable & Classification & Factor \\
\hline \multirow{4}{*}{ Size } & \multirow{4}{*}{ Median } & $\mathrm{SMB}_{\mathrm{B} / \mathrm{M}}=(\mathrm{SH}+\mathrm{SN}+\mathrm{SL}) / 3-(\mathrm{BH}+\mathrm{BN}+\mathrm{BL}) / 3$ \\
\hline & & $\mathrm{SMB}_{\text {Luc }}=(\mathrm{SR}+\mathrm{SN}+\mathrm{SW}) / 3-(\mathrm{BR}+\mathrm{BN}+\mathrm{BW}) / 3$ \\
\hline & & $\mathrm{SMB}_{\mathrm{Inv}}=(\mathrm{SC}+\mathrm{SN}+\mathrm{SA}) / 3-(\mathrm{BC}+\mathrm{BN}+\mathrm{BA}) / 3$ \\
\hline & & $\mathrm{SMB}=\left(\mathrm{SMB}_{\mathrm{B} / \mathrm{M}}+\mathrm{SMB}_{\mathrm{Luc}}+\mathrm{SMB}_{\text {Inv }}\right) / 3$ \\
\hline Book-to-market & 30th and 70th percentiles & $\mathrm{HML}=(\mathrm{SH}+\mathrm{BH}) / 2-(\mathrm{SL}+\mathrm{BL}) / 2$ \\
\hline Momentum & 30th and 70th percentiles & $\mathrm{WML}=(\mathrm{SWin}+\mathrm{BWin}) / 2-(\mathrm{SLos}+\mathrm{BLos}) / 2$ \\
\hline Profitability & 30th and 70th percentiles & $\mathrm{RMW}=(\mathrm{SR}+\mathrm{BR}) / 2-(\mathrm{SW}+\mathrm{BW}) / 2$ \\
\hline Investment & 30th and 70th percentiles & $\mathrm{CMA}=(\mathrm{SC}+\mathrm{BC}) / 2-(\mathrm{SA}+\mathrm{BA}) / 2$ \\
\hline
\end{tabular}

Note: The Variable column indicates the characteristic of the stock whose respective factor seeks to capture the effect. The Classification column indicates the breakpoints used in the division of stocks. Finally, the Factor column presents the formula for calculating the returns of the factors.

Source: Elaborated by the authors.

In addition to the factors mentioned above, the firststep models also incorporate the market risk premium, obtained by the difference between the monthly return on the market proxy portfolio and the return on the risk-free asset. For the market portfolio, we considered monthly returns, weighted by the monthly market value, on a portfolio composed of all stocks in the sample in each year of the study period. For the risk-free interest rate, the one-month US Treasury bill rate was considered. We opted to use this rate because it was necessary to assume that the risk-free asset had a zero probability of default. In this way, the high sovereign rating of the United States and the fact that US rates are independent of our study sample markets make the one-month Treasury bill rate an adequate proxy to the risk-free interest rate.

\subsubsection{Dependent variables}

To test the explanatory power of the estimated models, we formed portfolios based on the characteristics of the sample's assets. The strategy adopted in the formation of these portfolios was similar to that of Fama and French (2015), with a double ranking of assets and three sets of portfolios formed to estimate the models tested in the study.

In the formation of portfolios, the stocks were initially ordered by size and separated into quintiles. Next, these quintiles were ordered by a second variable, namely: book-to-market, investment and profitability; and then divided again into quintiles.

This process generated 25 portfolios for each of the three variables considered in the second classification. In other words, 75 portfolios were formed. The number 
of stocks comprising these portfolios ranged from a minimum of 10 to a maximum of 19 , with an average of 14.77 stocks. The dependent variables of the first-step models were then represented by the excess return on these portfolios in relation to the risk-free interest rate. To calculate the portfolio returns, we used the log returns of the stocks weighted by their market value in relation to the portfolio's total market value. For the second-step models, the dependent variable was represented by the average of the excess return on each of these 75 portfolios over the sample period.

\subsection{Validation and Robustness Tests of the Models}

An important step in studies involving the estimation of econometric models is carrying out diagnostic tests of their underlying assumptions to verify their validity. Thus, in the models estimated in the second step of the Fama and MacBeth (1973) methodology, which we applied in this study, the presence of the following problems were verified: (i) multicollinearity, using the Variance Inflation Factor
(VIF) test; (ii) heteroscedasticity, using the Breusch-Pagan test; (iii) autocorrelation, through the Durbin-Watson test.

In addition to the problems assessed by the tests described above, Collot and Hemauer (2020) point out that the use of the coefficients obtained in first-step regressions as explanatory variables in second-step regressions makes the models susceptible to bias due to measurement errors in the first-step regressions. Thus, the second-step regressions were estimated using both the Ordinary Least Squares Method (OLS) and the Generalized Method of Moments (GMM). The Hausman specification test was then used to assess the consistency of the OLS estimator.

Furthermore, we used the Gibbons, Ross and Shanken (1989) (GRS) test to assess the performance of the models estimated in the first step of the Fama and MacBeth (1973) methodology in explaining the returns on each of the 75 portfolios used as the models' dependent variable. Finally, to verify the robustness of the results, the estimation was performed again by dividing the sample into two equal sub-periods of 108 months, namely: July 2000 to June 2009 and July 2009 to June 2018.

\section{ANALYSIS OF RESULTS}

\subsection{Returns}

Initially, we analyze the characteristics of portfolios whose excess returns were used as a dependent variable in the models, or left-hand-side portfolios (LHS). Table 6 shows the average of the characteristics used to form the portfolios, with the average for size shown on the left and, on the right, the average for the second variable considered in the formation of each portfolio group.

In interpreting the values on the left of Table 6, it is interesting to analyze the average sizes in each row, since they express the behavior of the portfolio size in relation to the average of the second variable considered in the ranking. On the right side of Table 6, it is important to observe, in each column, how the average of the second variable considered in the ranking behaved in relation to the size of the portfolio assets. The results presented in both sides of Table 6, when observed together, show the relationship established between the variables used in the ranking.

Table 6 results allow us to infer that there is a positive relationship between size and investment, and also between size and profitability, as the high portfolios for these two variables always presented a larger average size compared with the low portfolios. In the matrices for the average size and for the average profitability Panel (c) - we find the only case in which a big portfolio has lower average profitability compared with the small portfolio of the same profitability group (big and high portfolio). As for the book-to-market ratio, there was a negative relationship between this index and size, as shown in Panel (a). This fact was already expected, as the market value is used in the denominator for calculating this index. 
Table 6

Average of the characteristics used to form the portfolios (left-hand-side variables)

Panel (a): Portfolios formed by size - book-to-market

\begin{tabular}{lcccccccccccc}
\hline & Size & \multicolumn{8}{c}{ Book-to-market } \\
\hline & Low & $\mathbf{2}$ & $\mathbf{3}$ & $\mathbf{4}$ & High & Low & $\mathbf{2}$ & $\mathbf{3}$ & $\mathbf{4}$ & High \\
\hline Small & 37.16 & 31.92 & 35.06 & 32.36 & 20.64 & 0.94 & 2.24 & 3.91 & 6.85 & 26.14 \\
\hline 2 & 202.19 & 190.58 & 195.20 & 181.38 & 174.20 & 0.56 & 1.08 & 1.71 & 2.88 & 9.48 \\
\hline 3 & 595.75 & 545.91 & 552.13 & 546.51 & 549.39 & 0.41 & 0.83 & 1.29 & 2.15 & 7.15 \\
\hline 4 & 1498.66 & 1441.27 & 1412.36 & 1333.77 & 1376.17 & 0.31 & 0.65 & 1.03 & 1.72 & 5.76 \\
\hline Big & 10532.17 & 8392.76 & 7629.42 & 7509.62 & 7404.11 & 0.24 & 0.47 & 0.73 & 1.21 & 3.12 \\
\hline
\end{tabular}

Panel (b): Portfolios formed by size - investment

\begin{tabular}{lccccccccccc}
\hline & Size & \multicolumn{10}{c}{ Investment } \\
\hline & Low & $\mathbf{2}$ & $\mathbf{3}$ & $\mathbf{4}$ & High & Low & $\mathbf{2}$ & $\mathbf{3}$ & $\mathbf{4}$ & High \\
\hline Small & 31.17 & 31.70 & 32.14 & 28.76 & 33.24 & -0.21 & -0.06 & 0.02 & 0.12 & 0.48 \\
\hline 2 & 182.68 & 182.43 & 194.30 & 196.38 & 188.30 & -0.16 & -0.02 & 0.05 & 0.14 & 0.49 \\
\hline 3 & 551.20 & 556.07 & 550.61 & 564.68 & 570.09 & -0.12 & -0.01 & 0.07 & 0.16 & 0.56 \\
\hline 4 & 1373.81 & 1418.07 & 1433.96 & 1404.19 & 1437.23 & -0.12 & 0.00 & 0.08 & 0.17 & 0.62 \\
\hline Big & 6286.97 & 8604.36 & 9039.85 & 9241.75 & 8381.72 & -0.10 & 0.01 & 0.09 & 0.18 & 0.55 \\
\hline
\end{tabular}

Panel (c): Portfolios formed by size - profitability

\begin{tabular}{lcccccccccccc}
\hline & Size & \multicolumn{10}{c}{ Profitability } \\
\hline & Low & $\mathbf{2}$ & $\mathbf{3}$ & $\mathbf{4}$ & High & Low & $\mathbf{2}$ & $\mathbf{3}$ & $\mathbf{4}$ & High \\
\hline Small & 27.97 & 30.23 & 35.01 & 34.76 & 29.30 & -0.76 & 0.01 & 0.10 & 0.18 & 0.96 \\
\hline 2 & 174.62 & 190.35 & 192.15 & 189.65 & 197.58 & -0.13 & 0.08 & 0.14 & 0.22 & 0.44 \\
\hline 3 & 528.38 & 571.35 & 562.52 & 545.58 & 584.12 & 0.00 & 0.11 & 0.17 & 0.25 & 0.57 \\
\hline 4 & 1391.35 & 1392.12 & 1395.13 & 1435.58 & 1454.04 & 0.03 & 0.13 & 0.19 & 0.28 & 0.68 \\
\hline Big & 5560.85 & 7312.36 & 7555.83 & 10434.41 & 10700.42 & 0.00 & 0.14 & 0.21 & 0.31 & 0.61 \\
\hline
\end{tabular}

Note: Average size values are shown in US\$ million. The portfolio's second variable average was weighted by market value, with the value observed for the variable concerned (of each stock) weighted by the ratio between the stock's market value and the total market value of the portfolio. In each of the panels in Table 6, the rows refer to the quintile by size and the columns to the quintile by the portfolios' second variable.

Source: Elaborated by the authors.

Next, the average and standard deviation of the excess return on the LHS portfolios are shown in Table 7. Each Panel presents the values for a different portfolio group, which are organized according to the variable used in the second ranking of the portfolio formation process. This analysis is relevant because it aims to identify possible patterns in the excess average return on the portfolios in relation to the variables used in the study.

Panel (a) of Table 7 presents the characteristics for the 25 portfolios formed using size and the book-tomarket ratio. In the columns of Table 7 , we can observe decreasing average returns as portfolios composed of stocks with higher market value are considered. For all book-to-market groups, the excess average return on big portfolios was lower than the average value for the small portfolio, a pattern similar to this was also observed by
Fama and French (2015) in developed markets and, in the context of Latin American emerging markets, by Cakici et al. (2013) and Leite et al. (2018). This result shows the presence of a size effect: investors demand a higher return as a premium for the higher risk of investing in stocks of companies with lower market capitalization.

It is also possible to observe the relationship established between return and the book-to-market ratio. As documented by Fama and French (2015) and by Cakici et al. (2013), we can perceive a trend of growing average returns when comparing the low and high book-tomarket ratio portfolios - which suggests the existence of a premium for investors adopting the strategy of investing in high book-to-market stocks (low price in relation to equity). It is also interesting to note that, similar to the results of Fama and French (2015), the effect of the book- 
to-market ratio is larger for the small portfolio group compared with the big portfolio group. For portfolios composed of stocks with lower market capitalization, the excess average return between the low and high portfolios grows from $0.8436 \%$ to $2.2637 \%$; while for the portfolios of stocks with higher market capitalization, the growth is from $0.4209 \%$ to $0.7213 \%$.

Similarly, when investment is used as the second variable in the formation of portfolios, as shown in Panel (b) of Table 7, we also observe a size effect, with a tendency for the average return to fall as portfolios composed of larger companies are considered. This relationship, however, is strictly decreasing only for investment group 4.

Panel (b) of Table 7 also shows that the average return on the low portfolios was higher than that of the high portfolios for the small, 2 and 3 size groups. This result differs from those of Fama and French (2015) - for developed markets - and those of Leite et al. (2018) - for Latin American emerging markets - both studies found higher average returns on low investment portfolios for all company size groups. This fact indicates that in the study sample there is no investment effect for the groups of stocks with the higher market capitalization.

For the portfolios formed according to profitability ranking, we can observe again that Panel (c) of
Table 7 shows a downward trend in returns as we consider portfolios composed of companies with higher market capitalization.

As documented by Fama and French (2015), when we consider the low and high extremes of profitability, the high group has always presented higher returns. It is also interesting to note the lower profitability effect for the big portfolios, with an average of $0.3354 \%$ for the low portfolio and $0.5517 \%$ for the high portfolio. This differs from the findings by Leite et al. (2018) for their Latin American sample. These authors observed higher average returns on low profitability portfolios.

Regarding the standard deviation of the excess return on the LHS portfolios, we observe that, in general, the small portfolios show a higher value for this measure compared with the big portfolios. These statistics corroborate the explanation for the presence of a size effect stating that the stocks of companies with lower market capitalization represent a higher risk for the investor. Also regarding the standard deviation, it is noteworthy that the results indicate that high book-to-market stocks represent a higher risk for the investor, as there is an upward trend in the standard deviation of the excess return on the high portfolios, compared with the low book-to-market portfolios.

Table 7

Descriptive statistics for the portfolios' monthly excess return

\begin{tabular}{|c|c|c|c|c|c|c|c|c|c|c|}
\hline \multicolumn{11}{|c|}{ Panel (a): Portfolios formed by size - book-to-market } \\
\hline \multicolumn{6}{|c|}{ Average } & \multicolumn{5}{|c|}{ Standard deviation } \\
\hline & Low & 2 & 3 & 4 & High & Low & 2 & 3 & 4 & High \\
\hline Small & 0.8436 & 1.6775 & 1.8581 & 2.0105 & 2.2637 & 9.0437 & 8.3484 & 9.6646 & 9.0696 & 8.4727 \\
\hline 2 & 1.2731 & 1.2952 & 1.7941 & 2.7619 & 1.8136 & 8.8339 & 7.4174 & 7.8206 & 8.5000 & 9.3274 \\
\hline 3 & 0.5159 & 1.3284 & 0.9358 & 1.5069 & 1.5458 & 8.1598 & 7.1883 & 8.0903 & 7.8140 & 8.6186 \\
\hline 4 & 0.9368 & 0.8417 & 1.1315 & 1.0921 & 1.1476 & 6.8290 & 6.6835 & 6.6623 & 7.3880 & 8.3322 \\
\hline Big & 0.4209 & 0.3880 & 0.4499 & 0.9325 & 0.7213 & 7.1090 & 6.6723 & 7.0559 & 7.9369 & 9.6569 \\
\hline \multicolumn{11}{|c|}{ Panel (b): Portfolios formed by size - investment } \\
\hline \multicolumn{3}{|c|}{ Average } & \multicolumn{8}{|c|}{ Standard deviation } \\
\hline & Low & 2 & 3 & 4 & High & Low & 2 & 3 & 4 & High \\
\hline Small & 1.6851 & 1.5126 & 1.6140 & 2.1141 & 1.6395 & 10.1082 & 8.7661 & 9.2969 & 8.2701 & 9.1962 \\
\hline 2 & 2.0772 & 1.7192 & 2.1014 & 1.7472 & 1.1454 & 9.0066 & 7.9045 & 9.0331 & 7.7572 & 8.8953 \\
\hline 3 & 1.1125 & 1.3214 & 1.4360 & 1.0629 & 0.7175 & 7.4009 & 7.6881 & 7.7626 & 7.8410 & 9.9135 \\
\hline 4 & 0.8620 & 1.0621 & 1.1183 & 1.0570 & 1.0488 & 7.3286 & 7.1012 & 6.5647 & 7.2185 & 8.2037 \\
\hline Big & 0.2964 & 0.8184 & 0.4306 & 0.7031 & 0.4818 & 7.5539 & 7.3562 & 7.9723 & 7.8180 & 8.4644 \\
\hline \multicolumn{11}{|c|}{ Panel (c): Portfolios formed by size - profitability } \\
\hline \multicolumn{3}{|c|}{ Average } & \multicolumn{8}{|c|}{ Standard deviation } \\
\hline & Low & 2 & 3 & 4 & High & Low & 2 & 3 & 4 & High \\
\hline Small & 1.5424 & 1.9536 & 1.3257 & 1.8692 & 1.9659 & 10.7182 & 8.8083 & 8.3039 & 7.7938 & 10.1249 \\
\hline 2 & 1.9084 & 1.2445 & 1.4908 & 1.6217 & 2.4318 & 9.7890 & 7.6491 & 7.4476 & 8.0016 & 8.9191 \\
\hline
\end{tabular}


Table 7

Cont.

Panel (c): Portfolios formed by size - profitability

\begin{tabular}{lcccccccccccc}
\hline & Average & \multicolumn{10}{c}{ Standard deviation } \\
\hline & Low & $\mathbf{2}$ & $\mathbf{3}$ & $\mathbf{4}$ & High & Low & $\mathbf{2}$ & $\mathbf{3}$ & $\mathbf{4}$ & High \\
\hline 3 & 0.7834 & 1.1481 & 1.4690 & 1.1965 & 1.1571 & 8.5374 & 7.7659 & 7.4743 & 7.2863 & 8.8785 \\
\hline 4 & 0.8954 & 0.7066 & 0.9109 & 1.2370 & 1.3156 & 7.0042 & 7.9307 & 6.4517 & 6.6165 & 7.8578 \\
\hline Big & 0.3354 & 0.4861 & 0.3406 & 0.9200 & 0.5517 & 8.9496 & 7.0948 & 7.0585 & 7.9690 & 7.4829 \\
\hline
\end{tabular}

Note: Average and standard deviation of the monthly excess percentage return on the 75 LHS portfolios in the period between July 2000 and June 2018. In each of the panels in Table 7, the rows refer to the quintile by size and the columns to the quintile by the portfolios' second variable.

Source: Elaborated by the authors.

\subsection{Factors}

After analyzing the characteristics and returns of the models' LHS portfolios, we assess in this section the right-hand-side factors (RHS) - independent variables of the first-step models.

Panel (a) of Table 8 presents the descriptive statistics for the factors used to estimate the three-factor model of Fama and French (1993) and the four-factor model of Carhart (1997). The SMB factor showed the highest average return among all factors $(0.8783 \%)$, contrary to the HML factor, which exhibited the lowest average return $(0.4460 \%)$. Regarding the statistical significance of the averages, at a level of $5 \%$, only the average for the SMB factor was statistically significant. In terms of the distribution of returns, the skewness and kurtosis statistics indicate that none of the factors follows a normal distribution, which in this study does not represent a problem, given the large sample size used.

Due to the differences in how the factors of Fama and French (2015) were built, which resulted in an SMB factor different from that used in the three- and four-factor models, the descriptive statistics of the factors used in the estimation of this model were separately presented in Panel (b) of Table 8.
These statistics showed again that the average return for the SMB factor was the highest among all factors $(0.9076 \%)$. In contrast, the average CMA return was the lowest $(0.1586 \%)$. Similar to what Panel (a) of this table shows, only the average for the SMB factor was statistically significant at the level of 5\%. Again, skewness and kurtosis indicate that the factors do not have a normal distribution.

On the one hand, the results presented in Table 8 differ from those by Fama and French (2015), who generally found lower, statistically significant averages for the factors in their study. Considering the factors built with a strategy similar to ours, the highest average documented by these authors was $0.50 \%$ for the market factor.

On the other hand, these statistics are in line with the results of other studies conducted with emerging markets samples, such as in Cakici et al. (2013) and Leite et al. (2018), who also found non-significant average monthly returns for the factors that were higher than those of Fama and French (2015). In the study by Cakici et al. (2013), the market factor showed the highest average among all tested factors (1.02\%); while in Leite et al. (2018) the highest average was observed for the size factor $(0.72 \%)$.

Table 8

Descriptive statistics for the factors' monthly returns

Panel (a): Descriptive statistics for the three-factor of Fama and French (1993) and for the momentum factor of Carhart (1997)

\begin{tabular}{|c|c|c|c|c|}
\hline & $\mathbf{R m}-\mathbf{R f}$ & SMB & HML & WML \\
\hline Average & 0.7750 & 0.8783 & 0.4460 & 0.5629 \\
\hline Standard deviation & 6.9756 & 2.7187 & 3.9544 & 4.8929 \\
\hline Skewness & -0.9295 & 0.0852 & -0.0215 & -0.3034 \\
\hline Kurtosis & 3.2129 & -0.0090 & 1.1484 & 1.6118 \\
\hline$t$-statistics & 1.6328 & 4.7480 & 1.6577 & 1.6909 \\
\hline$P$-value & 0.1040 & 0.0000 & 0.0988 & 0.0923 \\
\hline
\end{tabular}


Table 8

Cont.

Panel (b): Descriptive statistics for the five-factor of Fama and French (2015)

\begin{tabular}{cccccc}
\hline & $\mathbf{R m}-\mathbf{R f}$ & SMB & HML & CMA & 0.1586 \\
\hline Average & 0.7750 & 0.9076 & 0.4460 & 4.1325 & 0.2749 \\
\hline $\begin{array}{c}\text { Standard } \\
\text { deviation }\end{array}$ & 6.9756 & 2.7721 & 3.9544 & 0.0445 \\
\hline Skewness & -0.9295 & 0.1468 & -0.0215 & 1.3586 \\
\hline Kurtosis & 3.2129 & -0.0359 & 1.1484 & 0.9242 \\
\hline$t$-statistics & 1.6328 & 4.8117 & 1.6577 & 0.3640 \\
\hline$P$-value & 0.1040 & 0.0000 & 0.0988 & 0.5733 \\
\hline
\end{tabular}

Note: Descriptive statistics for the factors' monthly returns (in percentages) in the period between July 2000 and June 2018. Panel (a) presents the descriptive statistics for the returns on the three-factor of Fama and French (1993) and the momentum of Carhart (1997). Panel (b) presents the descriptive statistics for the returns on the five-factor of Fama and French (2015).

Source: Elaborated by the authors

In order to assess whether the RHS factors represent different dimensions of systematic risk, we performed an analysis of the correlations between the factors. Panel (a) of Table 9 shows the correlations estimated for the factors of the Fama and French (1993) and Carhart (1997) models. Our analysis showed that the HML and Market $\left(\mathrm{R}_{\mathrm{m}}-\mathrm{R}_{\mathrm{f}}\right)$ factors have the strongest and most positive relationship, with a coefficient of 0.4043 . In contrast, the WML and HML factors showed the strongest negative association, with a coefficient of -0.3166 .

The correlations between the returns for the factors used to estimate the Fama and French (2015) model are shown in Panel (b) of Table 9. The strongest negative relationship was observed between the HML and RMW factors $(-0.2699)$. It is also interesting to note the correlation of -0.2243 between the RMW and CMA factors.

Overall, these results suggest a low degree of association between the factors of the Fama and French (1993), Carhart (1997) and Fama and French (2015) models. In other words, our results suggest that they represent different dimensions of systematic risk. Foye (2018) and Leite et al. (2018) are examples of studies that also examined the Fama and French (2015) model in the context of Latin American emerging markets, and they also observed a low degree of association between the factors used in the five-factor model.

Table 9

Correlation between systematic risk factors

\begin{tabular}{cccc}
\hline \multicolumn{1}{l}{ Panel (a): Correlation between the three-factor of Fama and French (1993) and the momentum factor of Carhart (1997) } \\
\hline & $\mathbf{R m}-\mathbf{R f}$ & $\mathbf{S M B}$ & $\mathbf{H M L}$ \\
\hline $\mathrm{Rm}-\mathrm{Rf}$ & 1 & & \\
\hline $\mathrm{SMB}$ & -0.1525 & 1 & 1 \\
\hline $\mathrm{HML}$ & 0.4043 & 0.0306 & -0.3166 \\
\hline $\mathrm{WML}$ & -0.1411 & -0.1187 & 1
\end{tabular}

Panel (b): Correlation between the five-factor of Fama and French (2015)

\begin{tabular}{|c|c|c|c|c|c|}
\hline & $R m-R f$ & SMB & HML & RMW & CMA \\
\hline Rm-Rf & 1 & & & & \\
\hline $\mathrm{SMB}$ & -0.1111 & 1 & & & \\
\hline HML & 0.4043 & 0.0359 & 1 & & \\
\hline RMW & -0.1346 & -0.2194 & -0.2699 & 1 & \\
\hline CMA & -0.2108 & 0.0428 & 0.1773 & -0.2243 & 1 \\
\hline
\end{tabular}

Note: Correlation matrix for factor returns in the sample period. Panel (a) presents the correlations between the three-factor of Fama and French (1993) and the momentum factor of Carhart (1997). Panel (b) presents the correlations between the five-factor of Fama and French (2015).

Source: Elaborated by the authors. 


\subsection{First-Step Regressions}

As pointed out by Fama and French (2015), the evaluation of an asset pricing model should focus mainly on its performance in explaining the excess return on the LHS portfolios. To this end, we used in this study the GRS test, which has the null hypothesis that the regression intercepts for a portfolio group are statistically equal to zero. Therefore, the best model evaluated using this test is the one with the highest $p$-value and the lowest test statistic. In addition to the GRS test, Table 10 presents other statistics for the model intercepts, which allow us to assess the magnitude of the returns left unexplained by the factor models, which are: i. $A\left|a_{i}\right|$-average of the absolute values of the intercepts found for the model in a given LHS portfolio group. For this statistic, lower values indicate a better model performance.

ii. $A\left|a_{i}\right| / A\left|r_{i}\right|$ - ratio between the absolute average of the intercepts - $A\left|a_{i}\right|-$ and the absolute value of the average deviation of the returns on each portfolio $i$ in relation to the average of the returns on all LHS portfolios formed using the same variables used to build the portfolio $i-\mathrm{A}\left|\mathrm{r}_{\mathrm{i}}\right|$. It shows the dispersion of the model intercepts in relation to the expected return for a LHS portfolio group, thus measuring how much of the returns on the LHS portfolios are left unexplained by the factor models.

Table 10

Descriptive statistics for the first-step regressions

\begin{tabular}{|c|c|c|c|c|c|c|}
\hline \multicolumn{7}{|c|}{ Panel (a): Portfolios formed by size - book-to-market } \\
\hline & GRS & $p$-value & $\mathbf{A}\left|\boldsymbol{\alpha}_{\mathrm{i}}\right|$ & $\mathbf{s}(\mathbf{\alpha})$ & $\mathrm{A}\left|\boldsymbol{\alpha}_{\mathrm{i}}\right| / \mathrm{A}\left|\mathbf{r}_{\mathrm{i}}\right|$ & $\mathbf{R}^{2}$ \\
\hline Three factors & 1.7815 & 0.0165 & 0.2731 & 0.3803 & 0.5676 & 0.7657 \\
\hline Four factors & 1.6918 & 0.0265 & 0.2600 & 0.3769 & 0.5402 & 0.7684 \\
\hline Five factors & 1.5884 & 0.0447 & 0.2547 & 0.3574 & 0.5292 & 0.7715 \\
\hline \multicolumn{7}{|c|}{ Panel (b): Portfolios formed by size - investment } \\
\hline & GRS & $p$-value & $\mathbf{A}\left|\boldsymbol{\alpha}_{\mathrm{i}}\right|$ & $\mathbf{s}(\mathbf{\alpha})$ & $\mathrm{A}\left|\boldsymbol{\alpha}_{\mathrm{i}}\right| / \mathrm{A}\left|\mathbf{r}_{\mathrm{i}}\right|$ & $\mathbf{R}^{2}$ \\
\hline Three factors & 1.1879 & 0.2548 & 0.2229 & 0.2996 & 0.5180 & 0.7265 \\
\hline Four factors & 1.5134 & 0.0641 & 0.2610 & 0.3565 & 0.6066 & 0.7315 \\
\hline Five factors & 1.1164 & 0.3277 & 0.2496 & 0.3140 & 0.5801 & 0.7574 \\
\hline \multicolumn{7}{|c|}{ Panel (c): Portfolios formed by size - profitability } \\
\hline & GRS & $p$-value & $\mathrm{A}\left|\boldsymbol{\alpha}_{\mathrm{i}}\right|$ & $\mathbf{s}(\boldsymbol{\alpha})$ & $\mathbf{A}\left|\boldsymbol{\alpha}_{\mathrm{i}}\right| / \mathbf{A}\left|\mathbf{r}_{\mathrm{i}}\right|$ & $\mathbf{R}^{2}$ \\
\hline Three factors & 1.4103 & 0.1029 & 0.2533 & 0.3359 & 0.5911 & 0.7441 \\
\hline Four factors & 1.3569 & 0.1300 & 0.2305 & 0.3288 & 0.5379 & 0.7475 \\
\hline Five factors & 1.1291 & 0.3139 & 0.2085 & 0.2515 & 0.4866 & 0.7600 \\
\hline
\end{tabular}

Note: The GRS and p-value columns refer to the results for the Gibbons, Ross and Shanken test. The columns A| $\alpha_{i} \mid$ and $R^{2}$ refer, respectively, to the average of the absolute values for the intercepts and the coefficient of determination of the models. Column $S\left(\alpha_{i}\right)$ presents the standard deviation of the models' intercept values. Column $A\left|\alpha_{i}\right| A\left|r_{i}\right|$ presents the ratio between the average absolute value of the intercepts and the average absolute value of the average return on the portfolio $i$ minus the average of the returns on all portfolios formed with the same variables used to build portfolio $i$.

Source: Elaborated by the authors.

The following analysis is mainly aimed at comparing the performance of the models in the different sets of factors tested to assess the impact of the inclusion of new factors on the models' predictive power. The GRS test statistics, presented in Table 10, show that the model with the highest $p$-value was composed of five factors for all LHS portfolio groups. This result is in line with those obtained by Fama and French (2015), providing evidence for the inclusion of investment and profitability factors in the model.

The worst performance was observed for the models based on book-to-market portfolios - Panel (a). It is 
interesting to note that the GRS null hypothesis was rejected at the significance level of $5 \%$ for all sets of factors of this portfolio group. For the other LHS portfolio groups, the null hypothesis could not be rejected, indicating that the models were able to fully explain the expected returns on the respective portfolios.

The values of the $A\left|a_{i}\right|$ presented in Table 10 favor the five-factor of Fama and French (2015) for the book-tomarket and profitability portfolios. However, as Panel (b) shows, for investment portfolios, the model that presented the lowest value for $\mathrm{A}\left|\mathrm{a}_{\mathrm{i}}\right|(0.2229)$ was composed of the three-factor Fama and French (1993).

For the $\mathrm{A}\left|\mathrm{a}_{\mathrm{i}}\right| \mathrm{A}\left|\mathrm{r}_{\mathrm{i}}\right|$ ratio, lower values mean that the model left a smaller portion of average returns unexplained. The $\mathrm{A}\left|\mathrm{a}_{\mathrm{i}} / \mathrm{A}\right| \mathrm{r}_{\mathrm{i}} \mid$ ratio also favored the five-factor model for the book-to-market and profitability portfolios in the second ranking. For investment portfolios, the model showing the lowest value for this statistic $(0.5158)$ was composed of the three-factor Fama and French (1993). It is important to note that the $\mathrm{A}\left|\mathrm{a}_{\mathrm{i}}\right|$ and $\mathrm{A}\left|\mathrm{a}_{\mathrm{i}}\right| / \mathrm{A}\left|\mathrm{r}_{\mathrm{i}}\right|$ statistics fulfill different objectives compared with the GRS test: while $\mathrm{A}\left|\mathrm{a}_{\mathrm{i}}\right|$ and $\mathrm{A}\left|\mathrm{a}_{\mathrm{i}}\right| / \mathrm{A}\left|\mathrm{r}_{\mathrm{i}}\right|$ are aimed at analyzing the portion of returns left unexplained by the models, the GRS test verifies whether the set of intercepts for a portfolio group is statistically equal to zero.

The analysis of the average $\mathrm{R}^{2}$ statistics in Table 10 shows that the results favors the Fama and French (2015) model for all LHS portfolio groups. The largest gain in explanatory power for this statistic was observed for the investment portfolios in the second ranking, with $\mathrm{R}^{2}$ jumping from 0.7265 for the three-factor model to 0.7557 for the five-factor model.
Our results corroborate those of other studies that analyzed returns on stocks of companies listed on stock exchanges in Latin America. Leite et al. (2018) and Foye (2018), for example, do not reject the GRS null hypothesis for the models, with the five-factor model being preferable to the three-factor model for the profitability and investment portfolios formed in the second ranking.

\subsubsection{Robustness analysis}

To verify the robustness of the first-step regressions' results, the models were estimated again with the sampling period segmented into two equal periods: (i) July 2000 to June 2009 (Pre-2009); and (ii) July 2009 to June 2018 (Post2009).

The robustness test results - Table 11 - show that, for all LHS portfolio groups, the models were better adjusted in the second sampling period. The largest gain was observed for investment portfolios in the second ranking highest GRS $p$-value between the two periods - Panel b). This result could be explained by a greater integration of the studied countries' markets into the global markets. Transactions in the emerging markets would thus be showing a behavior more similar to that of the markets for which the models were proposed.

Again, the five-factor model showed the best performance both in the GRS test and in the A $\left|\alpha_{i}\right|$ statistic. As Panel (c) of Table 11 shows, the only exception was the profitability portfolios, as the GRS test statistics ( $p$-value $=0.2182$ ) for the post-2009 period suggested that the four-factor model of Carhart (1997) performed better.

\section{Table 11}

Robustness tests of model performance: estimates for two sub-periods

\begin{tabular}{|c|c|c|c|c|c|c|}
\hline \multicolumn{7}{|c|}{ Panel (a): Portfolios formed by size - book-to-market } \\
\hline & \multicolumn{3}{|c|}{ Pre-2009 } & \multicolumn{3}{|c|}{ Post-2009 } \\
\hline & GRS & $p$-value & $A\left|\alpha_{i}\right|$ & GRS & $p$-value & $A\left|\boldsymbol{\alpha}_{i}\right|$ \\
\hline Three factors & 1.8508 & 0.0207 & 0.4563 & 1.8030 & 0.0255 & 0.25840 \\
\hline Four factors & 1.7970 & 0.0264 & 0.4422 & 1.5870 & 0.0636 & 0.28518 \\
\hline Five factors & 1.7163 & 0.0375 & 0.4412 & 1.5711 & 0.0683 & 0.23002 \\
\hline \multicolumn{7}{|c|}{ Panel (b): Portfolios formed by size - investment } \\
\hline & \multicolumn{3}{|c|}{ Pre-2009 } & \multicolumn{3}{|c|}{ Post -2009 } \\
\hline & GRS & $p$-value & $\mathbf{A}\left|\boldsymbol{\alpha}_{\mathrm{i}}\right|$ & GRS & $p$-value & $A\left|\alpha_{i}\right|$ \\
\hline Three factors & 1.1960 & 0.2694 & 0.3737 & 0.8840 & 0.6246 & 0.27889 \\
\hline Four factors & 1.1897 & 0.2754 & 0.3900 & 0.8505 & 0.6674 & 0.28041 \\
\hline Five factors & 1.1400 & 0.3223 & 0.3704 & 0.6742 & 0.8662 & 0.25086 \\
\hline
\end{tabular}


Table 11

Cont.

\begin{tabular}{lcccccc}
\hline \multicolumn{1}{l}{ Panel (c): Portfolios formed by size - profitability } & & & & \\
\hline & & Pre-2009 & & Post -2009 & \\
\hline & GRS & $\boldsymbol{p}$-value & $\mathbf{A}\left|\boldsymbol{\alpha}_{\mathrm{i}}\right|$ & $\mathbf{G R S}$ & $\boldsymbol{p}$-value & $\mathbf{A}\left|\boldsymbol{\alpha}_{\mathrm{i}}\right|$ \\
\hline Three factors & 1.8827 & 0.0180 & 0.5128 & 1.4471 & 0.1101 & 0.40548 \\
\hline Four factors & 1.8353 & 0.0224 & 0.5084 & 1.2600 & 0.2182 & 0.40767 \\
\hline Five factors & 1.6781 & 0.0440 & 0.4974 & 1.2960 & 0.1932 & 0.32200 \\
\hline
\end{tabular}

Note: The GRS and p-value columns refer to the results for the Gibbons, Ross and Shanken test. The columns $A\left|\alpha_{i}\right|$ and $R^{2}$ refer, respectively, to the average of the absolute values for the intercepts and the coefficient of determination of the models. Column $S\left(\alpha_{i}\right)$ presents the standard deviation of the models' intercept values. Column $A\left|\alpha_{i}\right| A\left|r_{i}\right|$ presents the ratio between the average absolute value of the intercepts and the average absolute value of the average return on the portfolio $i$ minus the average of the returns on all portfolios formed with the same variables used to build portfolio $i$.

Source: Elaborated by the authors.

\subsection{Second-Step Regressions}

The second-step cross-section regressions were estimated using the average of the excess return for each of the 75 LHS portfolios as a dependent variable over the sample period and the coefficients estimated in the firststep regressions as independent variables.

Table 12

VIF of the second-step regressions' explanatory variables

\begin{tabular}{cccr}
\hline Variable & Three factors & Four factors & Five factors \\
\hline$\beta$ & 1.0235 & 1.0216 & 1.0246 \\
\hline s & 1.0303 & 1.0678 & 1.0452 \\
\hline h & 1.0105 & 1.0055 & 1.0378 \\
\hline W & - & 1.0475 & - \\
r & - & - & 1.0544 \\
\hline C & - & - & 1.0299 \\
\hline
\end{tabular}

Source: Elaborated by the authors.

Table 13 shows the results of the Breusch-Pagan, Durbin-Watson and Hausman tests, used to detect heteroscedasticity, autocorrelation and endogeneity problems, respectively. It is noteworthy that the results obtained show no autocorrelation problems in the models, whereas the BP test result attested the presence of heteroscedasticity for the five-factor model, with a $p$-value of 0.0457 . In view of the validation tests' results, it was necessary to correct standard errors only for the
Before interpreting the results for the models, it is necessary to analyze the validation tests' results. Table 12 shows the Variance Inflation Factor (VIF) for the explanatory variables used in the models. It is interesting to note that this statistic indicates no multicollinearity for the models, given that, as Wooldridge (2010) points out, it is normally assumed that VIF values higher than 10 indicate multicollinearity. 
Table 13

Validation tests of the second-step regressions

\begin{tabular}{cccccccc}
\hline Model & DW & $\boldsymbol{p}$-value & BP & $\boldsymbol{p}$-value & Hausman & $\boldsymbol{p}$-value & 0.4834 \\
\hline Three factors & 2.0480 & 0.5743 & 5.3742 & 0.1464 & 0.4555 & 2.8188 & 0.5886 \\
\hline Four factors & 2.0686 & 0.6200 & 9.1008 & 0.0486 & 3.4976 & 0.6237 \\
\hline Five factors & 2.1301 & 0.7375 & 11.3020 & 0.0457 \\
\hline
\end{tabular}

Note: Test statistics and p-value calculated for the Durbin-Watson (DW), Breusch-Pagan (BP) and Hausman tests of the secondstep equations estimated in the study.

Source: Elaborated by the authors.

Table 14 shows the results of the cross-section regressions. All factors used in the estimation of the three-factor model showed to be significant - Panel (a). After adding the momentum factor to this model Panel (b) - its coefficient showed no significance. When the five-factor model was estimated, the coefficient for profitability was significant only at the level of $10 \%$; and the investment coefficient was not significant. Despite the fact that the new factors included in the Fama and French (2015) model showed no significance for the tested models, this was the model with the greatest explanatory power in the second-step regressions, with an adjusted $\mathrm{R}^{2}$ of 0.6995 .

Finally, it is interesting to note that the models' intercepts showed to be highly significant in all cases. This suggests that the factors tested were not sufficient to explain the excess cross-section return for the LHS portfolios. The intercept would thus reflect the variations in the return resulting from relevant factors not included in the model.

Table 14

Results of the factor models' cross-section regressions

Panel (a): Three-factor Fama and French (1993)

\begin{tabular}{cccccc}
\hline & $\gamma_{0}$ & $\gamma_{1}$ & $\gamma_{2}$ & $\gamma_{3}$ & Adjusted R $^{2}$ \\
\hline Coef & 1.6041 & -0.9308 & 0.9527 & 0.3226 & 0.6555 \\
\cline { 1 - 4 } -val & 0.0000 & 0.0002 & 0.0000 & 0.0082 & \\
\hline
\end{tabular}

Panel (b): Four-factor Carhart (1997)

\begin{tabular}{ccccccc}
\hline & $\gamma_{0}$ & $\gamma_{1}$ & $\gamma_{2}$ & $\gamma_{3}$ & $\gamma_{4}$ & Adjusted R $^{2}$ \\
\hline Coef & 1.5997 & -0.9217 & 0.9784 & 0.3582 & 0.2020 & 0.6606 \\
\hline$p$-val & 0.0000 & 0.0003 & 0.0000 & 0.0037 & 0.5001 &
\end{tabular}

Panel (c): Five-factor Fama and French (2015)

\begin{tabular}{cccccccc}
\hline & $\gamma_{0}$ & $\gamma_{1}$ & $\gamma_{2}$ & $\gamma_{3}$ & $\gamma_{5}$ & $\gamma_{6}$ & Adjusted R $^{2}$ \\
\hline Coef & 1.7301 & -1.0481 & 0.9246 & 0.3988 & 0.2946 & -0.0410 \\
\hline$p$-val & 0.0000 & 0.0002 & 0.0000 & 0.0018 & 0.0774 & 0.7821 & 0.6958 \\
\hline
\end{tabular}

Note: Coefficient (Coef), $p$-value ( $p$-val) and coefficient of determination $\left(R^{2}\right)$ of the second-step cross-section regressions. The coefficients of the market, size, book-to-market, momentum, profitability and investment factors are identified in the table by $\gamma_{1}$, $\gamma_{2}, \gamma_{3}, \gamma_{4}, \gamma_{5}$ and $\gamma_{6}$, respectively. The models' intercept is identified by $\gamma_{0}$.

Source: Elaborated by the authors. 


\section{FINAL CONSIDERATIONS}

The relevance of this study stems from its examination of the differences between the capital markets of developed countries and emerging countries, which affect the results and the predictive power of asset pricing models - which were mostly proposed for developed markets - and, consequently, the investor's decision-making process. Thus, this study had as its main objective testing the five-factor model of Fama and French (2015) using a sample composed of stocks of companies listed in the stock markets of Brazil, Chile, Colombia, Mexico and Peru. At the same time, in order to allow comparing the results for models with different sets of factors, the models of Carhart (1997) and Fama and French (1993) were also estimated.

It is interesting to note that the descriptive statistics of the returns for the factors built to estimate the models showed that the averages found were, in general, higher than those found by Fama and French (2015), with only the SMB factor average showing statistical significance. These results corroborate those of other studies on asset pricing in emerging markets, such as those by Cakici et al. (2013) and Leite et al. (2018); and they indicate the existence of a greater impact of the variables used to build the factors on the returns on the assets traded in these markets.

Regarding the results of the first-step regressions estimated, the descriptive statistics indicated, in general, that the five-factor model performed better. The $p$-values of the GRS statistics were always higher for the five-factor model, with the result for the model applied to portfolios formed by size and book-to-market the only case in which the null hypothesis of the test was rejected (0.0447).

To test the robustness of the results, the models were estimated again by segmenting the sampling period into two sub-periods of equal duration. The robustness test results showed that the models performed better in the second half of the sampling period, which could be explained by the greater integration of the markets studied into the global markets. With regard to the different model compositions tested, the results again indicated that the model composed of the five factors of Fama and French (2015) performed better for the sample.

Finally, the cross-section regressions, or second step models, were tested to verify whether the coefficients obtained in the first step were able to explain the excess average return on the LHS portfolios. The results favored the Fama and French (2015) model, given its higher adjusted $\mathrm{R}^{2}$. However, the estimates of the models studied clearly showed that none of them was able to fully explain the excess return on the LHS portfolios. Our findings, therefore, suggest that the factors tested could not fully describe the cross-section returns for the sample assets. This reinforces the need to carry out further studies with the inclusion of other factors in the models, such as market liquidity and informational risk.

The study results contribute to a better understanding of the relevant factors in emerging markets and their impact on asset pricing; and they help financial market players to improve their decision-making process both in the composition and in the assessment of the performance of their investment portfolios in view of the exposure to different sources of systematic risk. With regard to the asset pricing literature, this article provides important contributions by analyzing a broad sample of stocks traded in different emerging markets in Latin America and by conducting an empirical test of the Fama and French (2015) model based on the Fama and MacBeth methodology (1973).

\section{REFERENCES}

Ali, F., Khurram, M. U. \& Jiang, Y. (2019). The five-factor asset pricing model tests and profitability and investment premiums: evidence from Pakistan. Emerging Markets Finance \& Trade, 1-23.

Cakici, N., Fabozzi, F. J., \& Tan, S. (2013). Size, value, and momentum in emerging market stock returns. Emerging Markets Review, 16, 46-65.

Cakici, N., Tang, Y., \& Yan, A. (2016). Do the size, value, and momentum factors drive stock returns in emerging markets? Journal of International Money and Finance, 69, 179-204.
Carhart, M. M. (1997). On persistence in mutual fund performance. Journal of Finance, 52(1), 57-81.

Collot, S., \& Hemauer, T. (2020). A literature review of new methods in empirical asset pricing: omitted-variable and errors-in-variable bias. Financial Markets and Portfolio Management.

Fama, E., \& French, K. (1992). The cross-section of expected stock returns. Journal of Finance, 47(2), 427-465.

Fama, E., \& French, K. (1993). Common risk factors in the returns on stocks and bonds. Journal of Financial Economics, 33(1), 3-56. 
Fama, E., \& French, K. (2004). The capital asset pricing model: theory and evidence. Journal of Economic Perspectives, 18(3), 25-46.

Fama, E., \& French, K. (2006). Profitability, investment and average returns. Journal of Financial Economics, 82(3), 491518.

Fama, E., \& French, K. (2008). Dissecting anomalies. Journal of Finance, 63(4), 1653-1678.

Fama, E., \& French, K. (2015). A five-factor asset pricing model. Journal of Financial Economics, 116(1), 1-22.

Fama, E., \& MacBeth, J. (1973). Risk, return and equilibrium: empirical tests. Journal of Political Economy, 81(3), 607-636.

Foye, J. (2018). A comprehensive test of the Fama-French fivefactor model in emerging markets. Emerging Markets Review, $37,199-222$.

Ganz, A. C. S., Schlotefeldt, J. O., \& Rodrigues Junior, M. M. (2020). Modelos de precificação de ativos financeiros e governança corporativa. Revista de Administração Mackenzie, 21(2), 1-27.

Gibbons, M., Ross, S., \& Shanken, J. (1989). A test of the efficiency of a given portfolio. Econometrica, 57(5), 1121-1152.

Hanauer, M. X., \& Linhart, M. (2015). Size, value, and momentum in emerging market stock returns: integrated or segmented pricing? Asia-Pacific Journal of Financial Studies, 44, 175-214.

Harvey, C. R. (1995). Predictable risk and returns in emerging markets. Review of Financial Studies, 8(3), 773-816.

Leite, A. L., Klotzle, M. C., Pinto, A. C. F., \& Silva, A. F. (2018). Size, value, profitability, and investment: evidence from emerging markets. Emerging Markets Review, 36, 45-59.
Lintner, J. (1965). The valuation of risk assets and the selection of risk investments in stock portfolios and capital budgets. Review of Economics and Statistics, 47(1), 13-37.

Merton, R. C. (1973). An intertemporal capital asset pricing model. Econometrica, 41(5), 867-887.

Mossin, J. (1966). Equilibrium in a capital asset market. Econometrica, 34(4), 768-783.

Novy-Marx, R. (2013). The other side of value: The gross profitability premium. Journal of Financial Economics, 108(1), $1-28$.

Ross, S. (1976). The arbitrage theory of capital asset pricing. Journal of Economic Theory, 13(3), 341-360.

Sharpe, W. F. (1964). Capital asset prices: a theory of market equilibrium under conditions of risk. Journal of Finance, 19(3), 425-443.

Siqueira, L. S., Amaral, H. F., \& Correia L. F. (2017). O efeito do risco de informação assimétrica sobre o retorno de ações negociadas na BM\&FBOVESPA. Revista Contabilidade \& Finanças, 28(75), 425-444.

Titman, S. K. C., Wei, J., \& Xie, F. (2004). Capital investments and stock returns. Journal of Financial and Quantitative Analysis, 39(4), 677-700.

Wooldridge, J. M. (2010). Introdução à econometria: uma abordagem moderna (4a ed.). São Paulo: Cengage Learning.

Xie, S., \& Qu, Q. (2016). The three-factor model and size and value premiums in China's stock market. Emerging Markets Finance \& Trade, 52(5), 1092-1105.

Zaremba, A., \& Czapkiewicz, A. (2017). Digesting anomalies in emerging European markets: a comparison of factor pricing models. Emerging Markets Review, 31, 1-15. 